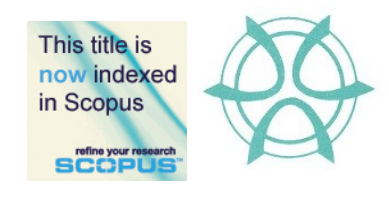

\title{
TRAVEL MODE CHOICE INTENTION IN REDUCING TRAFFIC CONGESTION IN KAJANG, SELANGOR
}

\author{
Wan Noratikah Wahidah Wan Ghazali ${ }^{1}$, Zakiah Ponrahono ${ }^{2}$, Syahriah Bachok ${ }^{3}$, \\ Amir Hamzah Sharaai ${ }^{4}$, Noor Suzilawati Rabe ${ }^{5}$, Nur Shazreena Mat Shukri ${ }^{6}$, \& \\ Yakin Nur Sunoto ${ }^{7}$ \\ 1,2,4,6,7 Department of Environment \\ Faculty of Forestry and Environment \\ UNIVERSITI PUTRA MALAYSIA \\ ${ }^{3,5}$ Department of Urban and Regional Planning \\ Kulliyyah of Architecture and Environmental Design \\ INTERNATIONAL ISLAMIC UNIVERSITY MALAYSIA
}

\begin{abstract}
The intentions behind a person's choice of transportation mode is vital information to have in strategic planning for a sustainable transportation system, and is very useful in predicting the behaviours of people. This paper was conducted to identify people's preferences of public transport. Using the Theory of Planned Behaviour (TPB) as the psychological determinant, three main indicators, attitude, subjective norm and perceived behavioural control (PBC), were explored to identify the mode choice of public transportation among the residents of Kajang. The data was obtained through questionnaires by employing a multistage sampling technique, where 348 respondents were approached. Partial Least Square (PLS) analysis showed that attitude was the dominant indicator among residents of Kajang for modes of public transport. This paper will contribute to the advancement of knowledge in the theory of mobility and travel behaviour, as well as act as baseline data for predicting people's travel behaviour in future mode shift strategies dealing with everyday issues of traffic, such as congestion.
\end{abstract}

Keywords: Travel intention, psychological mechanism, Theory of Planned Behaviour, public transport

\footnotetext{
${ }^{2}$ Lecturer at Universiti Putra Malaysia. Email: zakh@upm.edu.my
} 
Wan Noratikah Wahidah Wan Ghazali, Zakiah Ponrahono, Syahriah Bachok, Amir Hamzah Sharaai, Noor Suzilawati Rabe., Nur Shazreena Mat Shukri, \& Yakin Nur Sunoto

Travel Mode Choice Intention in Reducing Traffic Congestion in Kajang, Selangor

\section{INTRODUCTION}

The current developments in the transportation sector have proven to be unsustainable, and require a change in people's travel behaviour to reduce traffic congestion. This is owing to the fact that road traffic has risen substantially over time as a result of most homes now owning two or more vehicles (Nasrudin, Abdullah \& Hoon Leh, 2017). Using public transport is a viable solution to the alarming trend of motorization (Suwardo et al., 2015). Focusing on mode choice behaviour for public transport is an important aspect of public transport planning, as it has a direct impact on shaping the structure of the urban transport system and forms the basis of urban public transport planning and management (Chen \& $\mathrm{Li}, 2017)$. However, a low percentage of public transport ridership impedes the achievement of objectives to reduce traffic congestion and air population (Ngah et al., 2020).

Due to the inefficiency of public transport, many people are forced to travel by car, which exacerbates traffic congestion. The modal share of public transport in Malaysia is currently over $20 \%$, which is a worrying indicator of the future of the country's urban transport system that needs to be reconsidered (Abdelfatah et al., 2015). According to previous research, the decision to use public transport is a difficult one that is influenced by a variety of circumstances. First, research by Kamaruddin, Osman, and Che Pei (2012), showed that 32.3\% of their sample size considered safety to be the most important factor affecting customer satisfaction in terms of public transportation. Furthermore, according to Eriksson and Forward (2011), buses are associated with delays and may not be available when you need them apart from not being able to cater for certain locations. Finally, Shaaban and Maher (2019) found that commuters who have to wait longer for public transportation are prone to higher levels of stress. It can be concluded that more congestion, a higher loss of productivity, poorer quality of life and lower levels of liveability and competitiveness may result from the lack of an effective public transport system (Abdelfatah et al., 2015). Hence, for wellfunctioning and sustainable cities, an effective public transportation network is required.

This paper focusses on the travel intentions behind public transportation usage among people living in Kajang, Selangor, with a particular emphasis on the relationship between psychological determinants and the final travel behaviour of the riders. Intention refers to what people intend their behaviour to be. The stronger the intent to perform the behaviour, the more likely it is the behaviour will be performed. It is important to recognise the intentions of people using public transport, as well as to meet the expectations of the public, because, in general, user satisfaction is the most important consideration of any service provider (Hamzah, Ayub \& Hilmi, 2015). 


\section{THEORITICAL FRAMEWORK}

Psychological predictors are critical for comprehending travel-related decisions, especially in the design and implementation of successful transportation policies aimed at reducing vehicle usage in cities (Garcia et al, 2019). Such predictors are defined through the Theory of Planned Behaviour (TPB), and often apply to travel research. This theory is a helpful conceptual framework for better understanding the complexities of human social behaviour (Ajzen, 1991). According to the TPB model, individuals' behavioural intentions are shaped by attitudes, subjective norms and perceived behavioural control (PBC) (Ambak et al., 2016). Behavioural intention, according to Ajzen (1991), is a cognitive representation of a person's willingness to perform a specific activity, and is seen as an immediate antecedent of actual behaviour. The intentions are the precursors to behaviour (Ambak et al., 2016). Attitude is the first predictor. Achaempong (2017) claims that attitude is the anticipation of all consequences an action or behaviour may result in, as well as a reflection of the personal values associated with these outcomes. Subjective norm, on the other hand, is described in Dill et al. (2014) as a person's view of whether or not those significant to them believe they should execute a behaviour. Last but not least, the third predictor, PBC, reflects a person's opinion of how easy or difficult it will be to accomplish a specific behaviour (Zailani et al., 2016). Overall, behavioural intention' will henceforth be referred to as 'travel intention' within this paper, as it is its appropriate name in the field of transportation.

\section{RESEARCH MODEL AND HYPOTHESES}

The TPB model was used to investigate the extent to which attitude, subjective norms and PBC directly impacted Kajang's residents' intentions to take public transport. Figure 1 illustrates the conceptual model:

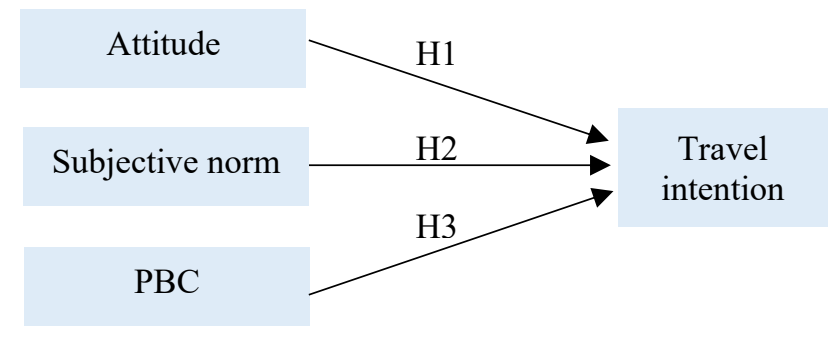

Figure 1: Travel Intention Conceptual Framework

To begin, a hypothesis for attitudes regarding travel intentions was created. According to Li et al. (2015), compared to subjective norms and PBC, attitude plays a much larger role in affecting the choice to take public transport, indicating 
Wan Noratikah Wahidah Wan Ghazali, Zakiah Ponrahono, Syahriah Bachok, Amir Hamzah Sharaai, Noor Suzilawati Rabe., Nur Shazreena Mat Shukri, \& Yakin Nur Sunoto

Travel Mode Choice Intention in Reducing Traffic Congestion in Kajang, Selangor

that improving travellers' attitudes can considerably boost their intentions to utilise public transportation. Zailani et al. (2016) discovered that attitude is a significant predictor of the intention to utilise public transport for a diverse range of objectives, explaining the $34.6 \%$ variation in intention found in their results.

Next, in terms of subjective norm, the majority of prior research has found a link between subjective norm and travel intention. The findings of $\mathrm{Fu}$ and Juan (2017), which studied travel intention alongside Customer Satisfaction Theory (CST), demonstrate that subjective norm is the most significant predictor of behavioural intention in regards to public transport usage. The study also claims that, while subjective norm does not influence target behaviour directly, it does have a beneficial impact on behavioural intention indirectly.

Last but not least, prior studies have revealed a link between PBC and intention as a third predictor in TPB. A study that predicted PBC as being mediated by travel intention in predicting travel behaviour is Zailani et al. (2016). PBC was shown to be a significant predictor of the intention to utilise public transportation for a variety of reasons, accounting for $49.8 \%$ of the variation in the study's results. Using an online and paper-based survey, Li et al. (2015) found that $\mathrm{PBC}$ partially explained the variance in intention discovered by the researcher. In addition to this, their quantitative survey analysis revealed that PBC has a greater impact on intention than on behaviour.

In conclusion, based on the discussions above, the hypotheses derived for this paper were:

H1: Attitudes have an effect on travel intentions for public transport.

H2: Subjective norms have an effect on travel intentions for public transport.

H3: PBC has an effect on travel intentions for public transport.

\section{RESEARCH METHODOLOGY}

\section{Research Area}

Kajang, Selangor was selected as the research area to study the growing problem of traffic congestion. Salem et al. (2011) highlighted that Kajang has a high rate of car ownership and use, making it the ideal place to look into the impact of parking policies for lowering car usage. Moreover, in terms of public transport usage, research by Norhisham et al. (2018), using the Quality of Service (QOS) system, found that Kajang was in dire need of improvement.

\section{Household Survey}

Kajang is divided into sixteen sections. Two sections, Section 4 and 7, were selected through the multistage sampling technique demonstrated in Fadzil \& Rashid (2012). Household surveys, utilising self-administered questionnaires, were collected from 360 respondents to gain a thorough understanding of the 
situation, however only 348 were deemed usable. The Partial Least Squares Structural Equation Modelling (PLS-SEM) method was used with the SmartPLS 3.0 software to assess the determinants influencing travel intention. In most cases, a PLS-SEM result is analysed and evaluated in two models: a measurement model (reliability and validity of the measure generated) and a structural model (hypothesis testing).

\section{THE RESULTS AND DISCUSSION}

\section{Measurement Model}

Figure 1, Figure 2 and Table 1 summarise the results of the measurement model. Recommended by Ramayah et al. (2018), the analytical measurement model included four assessments: examining indicator loadings; testing the reliability of internal consistency; evaluating convergent validity; and evaluating discriminant validity. According to Hussain et al. (2018), the appropriate cut off value for indicator loading is 0.7. Owing to an indicator loading of less than 0.7 (Figure 1), one item from PBC (pbc-3) was removed from the model.

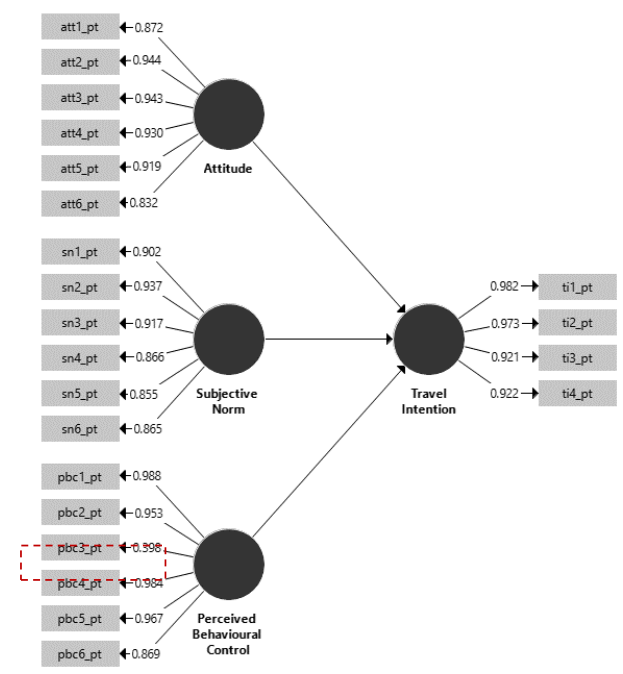

Figure 1: Initial Indicator Loading 
Wan Noratikah Wahidah Wan Ghazali, Zakiah Ponrahono, Syahriah Bachok, Amir Hamzah Sharaai, Noor Suzilawati Rabe., Nur Shazreena Mat Shukri, \& Yakin Nur Sunoto

Travel Mode Choice Intention in Reducing Traffic Congestion in Kajang, Selangor

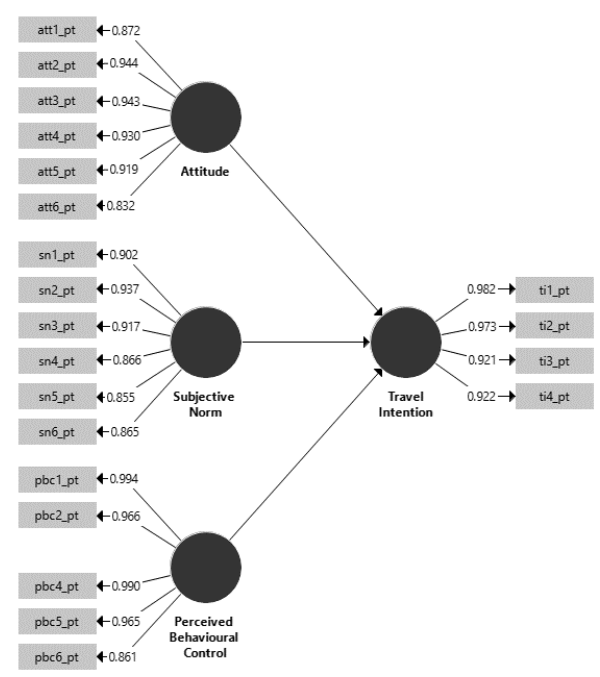

Figure 2: Final Indicator Loading

For the remaining items (Figure 2), Cronbach's alpha and composite reliability (CR) were used to measure their internal consistency reliabilities. This paper relied on Chen and Yan's (2019) accepted value of $>0.7$ for both Cronbach's alpha and CR. Convergent validity is the initial stage in determining validity. It was determined by computing the AVE value for the psychological construct for public transportation. An acceptable AVE score is 0.50 or above, which indicates that the construct explains over $50 \%$ of the variation found in its components on average (Sarstedt et al., 2014). Cronbach's alpha, CR and AVE values for this study's construct are listed in Table 1.

Table 1: Cronbach's alpha, CR, and AVE

\begin{tabular}{cccc} 
Variable & Cronbach's Alpha & CR & AVE \\
\hline Attitude & 0.957 & 0.966 & 0.824 \\
PBC & 0.977 & 0.982 & 0.915 \\
Subjective norm & 0.948 & 0.958 & 0.794 \\
Travel intention & 0.964 & 0.974 & 0.903 \\
\hline
\end{tabular}

After construct reliability and convergent validity have been proven, the discriminant validity of the construct must be evaluated. The discriminant validity was assessed using the Fornell and Larcker criteria, as well as through cross-loadings (Hussain et al., 2018; Hair et al., 2011). According to Xin et al. (2019), the square root of the AVE for the measured variables should be larger than their correlation coefficients, suggesting a strong discriminant validity for 
the Fornell and Larcker criteria. To calculate cross-loadings, however, each indicator loading must be at their highest for their assigned sub-construct on the same row (Hair et al., 2011). Table 2 and Table 3 showcase this study's discriminant validity results. The psychological construct of this study successfully attained acceptable discriminant validity, as seen in the two tables.

Table 2: Fornell and Lacker Criterion

\begin{tabular}{ccccc}
\hline Variable & Attitude & PBC & $\begin{array}{c}\text { Subjective } \\
\text { Norm }\end{array}$ & $\begin{array}{c}\text { Travel } \\
\text { behaviour }\end{array}$ \\
\hline Attitude & 0.908 & & & \\
PBC & 0.360 & 0.957 & & \\
Subjective Norm & 0.425 & 0.246 & 0.891 & \\
Travel intention & 0.719 & 0.464 & 0.561 & 0.950 \\
\hline
\end{tabular}

Table 3: Cross Loading

\begin{tabular}{ccccc}
\hline & Attitude & PBC & $\begin{array}{c}\text { Subjective } \\
\text { Norm }\end{array}$ & $\begin{array}{c}\text { Travel } \\
\text { intention }\end{array}$ \\
\hline att1_pt & $\mathbf{0 . 8 7 2}$ & 0.257 & 0.336 & 0.545 \\
att2_pt & $\mathbf{0 . 9 4 4}$ & 0.393 & 0.398 & 0.672 \\
att3_pt & $\mathbf{0 . 9 4 3}$ & 0.380 & 0.400 & 0.722 \\
att4_pt & $\mathbf{0 . 9 3 0}$ & 0.325 & 0.365 & 0.671 \\
att5_pt & $\mathbf{0 . 9 1 9}$ & 0.272 & 0.399 & 0.663 \\
att6_pt & $\mathbf{0 . 8 3 2}$ & 0.321 & 0.413 & 0.619 \\
\hline pbc1_pt & 0.352 & $\mathbf{0 . 9 9 4}$ & 0.241 & 0.453 \\
pbc2_pt & 0.405 & $\mathbf{0 . 9 6 6}$ & 0.251 & 0.483 \\
pbc4_pt & 0.398 & $\mathbf{0 . 9 9 0}$ & 0.270 & 0.499 \\
pbc5_pt & 0.351 & $\mathbf{0 . 9 6 5}$ & 0.257 & 0.455 \\
pbc6_pt & 0.134 & $\mathbf{0 . 8 6 1}$ & 0.115 & 0.267 \\
\hline sn1_pt & 0.357 & 0.123 & $\mathbf{0 . 9 0 2}$ & 0.481 \\
sn2_pt & 0.383 & 0.158 & $\mathbf{0 . 9 3 7}$ & 0.522 \\
sn3_pt & 0.375 & 0.172 & $\mathbf{0 . 9 1 7}$ & 0.508 \\
sn4_pt & 0.328 & 0.226 & $\mathbf{0 . 8 6 6}$ & 0.403 \\
sn5_pt & 0.300 & 0.221 & $\mathbf{0 . 8 5 5}$ & 0.402 \\
sn6_pt & 0.482 & 0.382 & $\mathbf{0 . 8 6 5}$ & 0.616 \\
\hline ti1_pt & 0.675 & 0.461 & 0.560 & $\mathbf{0 . 9 8 2}$ \\
ti2_pt & 0.648 & 0.466 & 0.546 & $\mathbf{0 . 9 7 3}$ \\
ti3_pt & 0.746 & 0.412 & 0.585 & $\mathbf{0 . 9 2 1}$ \\
ti4_pt & 0.654 & 0.424 & 0.425 & $\mathbf{0 . 9 2 2}$ \\
\hline
\end{tabular}


Wan Noratikah Wahidah Wan Ghazali, Zakiah Ponrahono, Syahriah Bachok, Amir Hamzah Sharaai, Noor Suzilawati Rabe., Nur Shazreena Mat Shukri, \& Yakin Nur Sunoto

Travel Mode Choice Intention in Reducing Traffic Congestion in Kajang, Selangor

\section{Structural Model/ Testing the Hypotheses of Travel Intentions regarding Public Transport}

Once all the constructs of measurement were proven to be reliable and valid, the structural model was evaluated. The significance of the results was determined using 500 samples bootstrapped from the initial 348 cases. The testing hypothesis for each path analysis suggested in the research hypotheses is shown in Figure 1. With 0.05 and $>1.96$, the P-values and T-values were both significant (Hair et. al., 2011). Surprisingly, all constructs of the study contributed significantly to the dependent variable. It was confirmed, by looking at the results in Table 4 and Figure 1 , that attitude $(\beta=0.522 ; \mathrm{T}=15.266 ; \mathrm{P}=0.000)$ had a substantial impact on travel intention. As a result, H1 received a lot of support. Furthermore, when looking at the positive effects of subjective norm on travel intention (H2), the data showed that subjective norms influenced travel intention favourably $(\beta=$ $0.205 ; \mathrm{T}=4.507 ; \mathrm{P}=0.000)$, and confirmed $\mathrm{H} 2$. $\mathrm{PBC}$ had a favourable and substantial impact on travel intention $(\beta=0.288 ; \mathrm{T}=6.437 ; \mathrm{P}=0.000)$, indicating that $\mathrm{H} 3$ was supported.

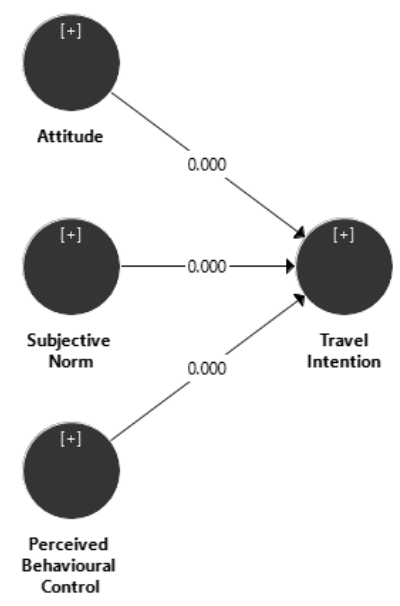

Figure 3: Path Analysis Assesment

Table 4: Testing Hypotheses

\begin{tabular}{ccccc}
\hline & Hypothesized Path & Path-Coefficient $(\beta)$ & T-Statistic & Result \\
\hline H1 & $\begin{array}{c}\text { Attitude }>\text { Travel } \\
\text { Intention }\end{array}$ & 0.522 & 15.266 & Significance \\
\hline H2 & $\begin{array}{c}\text { Subjective Norm }> \\
\text { Travel Intention }\end{array}$ & 0.205 & 4.507 & Significance \\
\hline H3 & PBC $>$ Travel Intention & 0.288 & 6.437 & Significance \\
\hline
\end{tabular}

Notes: Significance at P-values $<0.05$ and T-values $>1.96$ 
According to Hussain et al. (2018), the value of beta $(\beta)$, or the path coefficient, denotes the expected variation that will be found in the dependent construct for every unit of variation in the independent construct; or, the greater the value of $\beta$, the stronger the effects of an independent construct on the dependent construct. In this paper, the results of $\beta$ (Table 4 ) show that, for every one unit rise in attitude, subjective norm and $\mathrm{PBC}$, the predictors contributed $0.522,0.205$ and 0.288 increases in travel intention, respectively. Attitude was the strongest predictor of travel intention in this study. This is consistent with most previous research ( $\mathrm{Li}$ et al., 2015; Zailani et al., 2016), which proves that improvements in travelling attitudes can significantly increase a person's intention to use public transportation. Overall, the goal of this paper was to determine the intenions behind using public transport in order to encourage more travellers to switch from private vehicles to public transport. Due to the importance of attitudes in social psychology, theories from that field may be beneficial to better understanding travel behaviour, and, as a result, developing more successful ways of modifying planning practices (Dill et al., 2014).

\section{CONCLUSION AND RECOMMENDATION}

This paper has highlighted the determinants affecting the intention behind travel mode choices by adopting psychological variables into the study's conceptual model. These determinants have been analysed using the Partial Least Squares Structural Equation Modelling (PLS-SEM) via the SmartPLS 3.0 software. Hence, the conclusions drawn from this paper are as follows:

1. The 348 participants of this study made for a sufficiently large sample size, as confirmed by the overall acceptable value for measurement and structural model.

2. All the variables had substantial impacts on public transportation users' travel intentions, with attitude being the most important predictor, followed by PBC and subjective norm.

More research should be conducted in the future to determine the impact of attributes related to people's decisions for using public transportation, such as travel characteristics or socio-demographic factors, in order to encourage people to use public transportation in Kajang, Selangor and other cities. Aside from that, this approach should be used in other cities and countries to analyse people's choices of transportation modes.

\section{REFERENCES}

Abdelfatah, A. S., Shah, M. Z., \& Che Puan, O. (2015). Evaluating the Sustainability of Traffic Growth in Malaysia. Journal of Traffic and Logistics Engineering, 3(1), 6 - 
Wan Noratikah Wahidah Wan Ghazali, Zakiah Ponrahono, Syahriah Bachok, Amir Hamzah Sharaai, Noor Suzilawati Rabe., Nur Shazreena Mat Shukri, \& Yakin Nur Sunoto

Travel Mode Choice Intention in Reducing Traffic Congestion in Kajang, Selangor

11. https://doi.org/10.12720/jtle.3.1.6-11

Acheampong, R. A. (2017). Towards Sustainable Urban Transportation in Ghana: Exploring Adults' Intention to Adopt Cycling to Work Using Theory of Planned Behaviour and Structural Equation Modelling. Transportation in Developing Economies, 3(2), 1-11. https://doi.org/10.1007/s40890-017-0047-8

Ajzen, I. (1991). The theory of planned behavior. Organizational Behavior and Human Decision Processes, 50(2), 179-211. https://doi.org/10.1016/0749-5978(91)90020

Ambak, K., Kasvar, K. K., Daniel, B. D., Prasetijo, J., \& Abd Ghani, A. R. (2016). Behavioral intention to use public transport based on theory of planned behavior. MATEC Web of Conferences, 47. https://doi.org/10.1051/matecconf/20164703008

Chen, H. K., \& Yan, D. W. (2019). Interrelationships between influential factors and behavioral intention with regard to autonomous vehicles. International Journal of Sustainable Transportation, 13(7), 511-527. https://doi.org/10.1080/15568318.2018.1488021

Chen, J., \& Li, S. (2017). Mode Choice Model for Public Transport with Categorized Latent Variables. Mathematical Problems in Engineering, 2017. https://doi.org/10.1155/2017/7861945

Dill, J., Mohr, C., \& Ma, L. (2014). How can psychological theory help cities increase walking and bicycling? Journal of the American Planning Association, 80(1), 3651. https://doi.org/10.1080/01944363.2014.934651

Eriksson, L., \& Forward, S. E. (2011). Is the intention to travel in a pro-environmental manner and the intention to use the car determined by different factors? Transportation Research Part D, 16, 372-376. https://doi.org/10.1016/j.trd.2011.02.003

Fadzil, M., \& Rashid, A. (2012). The Implementation of Systematic Sampling Technique for Migration Behavioural Survey in Klang Valley. (December), 1-7

Fu, X., \& Juan, Z. (2017). Exploring the psychosocial factors associated with public transportation usage and examining the "gendered" difference. Transportation Research Part A: Policy and Practice, 103, 70-82. https://doi.org/10.1016/j.tra.2017.05.017

García, J., Mars, L., Arroyo, R., Casquero, D., di Ciommo, F., \& Ruiz, T. (2019). Personal values, attitudes and travel intentions towards cycling and walking, and actual behavior. Sustainability (Switzerland), 11(13), 1-20. https://doi.org/10.3390/su11133574

Hair, J. F., Ringle, C. M., \& Sarstedt, M. (2011). PLS-SEM: Indeed a silver bullet. Journal of Marketing Theory and Practice, 19(2), 139-152. https://doi.org/10.2753/MTP1069-6679190202

Hussain, S., Fangwei, Z., Siddiqi, A. F., Ali, Z., \& Shabbir, M. S. (2018). Structural Equation Model for evaluating factors affecting quality of social infrastructure projects. Sustainability $\quad$ (Switzerland), $10(5), \quad 1-25$. https://doi.org/10.3390/su10051415

Kamaruddin, R., Osman, I., \& Che Pei, C. A. (2012). Public Transport Services in Klang Valley: Customer Expectations and Its Relationship Using SEM. Procedia - Social and Behavioral Sciences, 36, 431-438. https://doi.org/10.1016/j.sbspro.2012.03.047

Li, L., Xiong, J., Chen, A., Zhao, S., \& Dong, Z. (2015). Key Strategies for Improving 
Public Transportation Based on Planned Behavior Theory: Case Study in Shanghai, China. Journal of Urban Planning and Development, 141(2), 4014019. https://doi.org/10.1061/(asce)up.1943-5444.0000203

Nasrudin, N., Abdullah, Y. A., \& Hoon Leh, O. L. (2017). Promoting Sustainable Travel Behavior Through Transport Policy Measures. Journal of the Malaysian Institute of Planners, 15(2), 85-96. https://doi.org/http://dx.doi.org/10.21837/pmjournal.v16.i6.270

Ngah, R., Putit, L., Mat, A., Abdullah, J., \& Ab Majid, R. (2020). Moderating Effect of Service Quality on Public Transport Travel Behaviour and Antecedents. Journal of the Malaysians Institute of Planners, 18(4), 80-91. https://doi.org/http://dx.doi.org/10.21837/pm.v18i14.819

Norhisham, S., Ismail, A., Sidek, L. M., Borhan, M. N., Zaini, N., \& Yen, A. T. G. (2018). Assessing Bus Performance Rating in Kajang, Selangor. IOP Conference Series: Earth and Environmental Science, 140(1). https://doi.org/10.1088/1755$1315 / 140 / 1 / 012076$

Ramayah, T., Hwa, Cheah., J. W., Chuah, F., Ting, H., \& Memon, M, A., (2018). Partial Least Squares Structural Equation Modelling (PLS-SEM) using SmartPLS 3.0: An Updated and Practical Guide to Statistical Analysis. Pearson Malaysia Sdn Bhd

Salem, A., Almeslati, I., Rahmat, R. O. K., Jaafar, O., \& Abuhamoud, M. A. (2011). The rise of the private car usage in Kajang, Malaysia: Role of parking policy on reducing car usage. Journal of Applied Sciences Research, 7(8), 1263-1268.

Shaaban, K., \& Maher, A. (2019). Using the theory of planned behavior to predict the use of an upcoming public transportation service in Qatar. Case Studies on Transport Policy. https://doi.org/10.1016/j.cstp.2019.11.001

Sarstedt, M., Ringle, C. M., Smith, D., Reams, R., \& Hair, J. F. (2014). Partial least squares structural equation modeling (PLS-SEM): A useful tool for family business researchers. Journal of Family Business Strategy, 5(1), 105-115. https://doi.org/10.1016/j.jfbs.2014.01.00

Xin, Z., Liang, M., Zhanyou, W., \& Hua, X. (2019). Psychosocial factors influencing shared bicycle travel choices among Chinese: An application of theory planned behavior. PLoS ONE, 14(1), 1-17. https://doi.org/10.1371/journal.pone.0210964

Zailani, S., Iranmanesh, M., Masron, T. A., \& Chan, T. H. (2016). Is the Intention to Use Public Transport for Different Travel Purposes Determined by Different Factors? $\begin{array}{lllll}\text { Transportation Research Part } & \text { D, 49, }\end{array}$ https://doi.org/10.1016/j.trd.2016.08.038 